\title{
ECONOMICAL DESIGN OF TIMBER-CONCRETE COMPOSITE BEAMS
}

\author{
Nikola Velimirović ${ }^{1}$, Ivan Stanimirović ${ }^{2}$, Dragoslav Stojić2 ${ }^{2}$ Nemanja Marković2,3 \\ Milivoje Milanović ${ }^{1}$ \\ ${ }^{1}$ State University of Novi Pazar \\ SERBia \\ ${ }^{2}$ University OF Niš \\ SERBia \\ ${ }^{3}$ Ruhr-University Bochum \\ Germany \\ (Received July 20I9)
}

\begin{abstract}
The aim of the presented study is to find the best solution for the cross-sectional dimensions of timber-concrete composite (TCC) beam by focusing on serviceability limit state verification and cost of the beam, simultaneously. The population of 10.000 samples of the observed variables according to the predetermined ranges using Monte Carlo sampling method was generated. In order to find a number of Pareto-optimal solutions on the Pareto front, the weighted sum method was employed using original algorithm. The results have shown that minimum relative cost of the TCC beam can be increased even by $26.6 \%$ if the rheological effects that are neglected by the Effective modulus method are counted in the calculation of the final deflection. The presented trade-off strategy in design of the TCC beams has shown that with the slight increase of relative cost compared to the minimum, it is possible to get Pareto optimal design solution of the TCC beam that has drastically decreased final deflection and therefore is a more reliable design solution.
\end{abstract}

KEYWORDS: Timber-concrete composite, multi-criteria decision-making, Pareto optimality, weighted sum method.

\section{INTRODUCTION}

The timber-concrete composite (TCC) structure is a structural system in which a timber beam is connected to an upper concrete flange using different types of connectors (Dias et al. 2015). They were able to exploit the best properties of both materials due to bending and tensile 
forces induced by gravity loads that are resisted primarily by the timber and compression by the concrete topping systems, while the connection system transmits the shear forces between the two components. Yeoh et al. (2011) provides survey on the timber-concrete composite research in the recent years. All around the world TCC systems have been used in structures during the last two decades. The main reason being that applications that could not have been built by timber alone now become possible with a use of TCC solution. In residential and office buildings, TCC systems have been extensively used for new floors and for upgrading and enhancing the performance of existing timber floors as the traditional timber floors may have excessive deflection, insufficient acoustic separation, and low fire resistance. TCC floors help in resolving all of these problems. Dias et al. (2016) gives a short overview of the use of TCC structural system in construction and then presents several case studies of its applications.

In structural design process, the design engineer has a task to offer the best technical solution of structure in accordance with the previously established terms and conditions. Civil engineering structures are generally designed based on prior work and experience, which often leads to the adoption of uneconomical solutions, because design engineers usually tend to maximally meet given design conditions. This comes as a direct result of the large safety and financial risks associated with civil engineering project because adopted structural design solution could drastically depart from the most favourable solution. Due to this fact, it is necessary to apply some of the optimization techniques in structural design process. However, the wide range of disparate and complex design requirements becomes a huge technical challenge when applying structural optimization within the design process of structures (Christensen and Klarbring 2009). Many of the structural design problems in civil engineering may be considered as multi objective problems. Design solution should satisfy confronting objectives at the same time. In order to solve this kind of problems, multi-criteria decision-making should be employed. In most cases, the ideal solution is not achievable. The problem of finding the best non-ideal solution usually does not have a unique solution. The level of optimality of a specific solution depends on the preferences made by the decision maker. The objective is the solution to be accepted as an effective result by the decision maker. In order to extent that objective, it is mandatory to contain those preferences as much as possible, in the computation process. There are numerous decision-making algorithms available in the literature. Probably the most known methods are the weighted sum method, ELECTRE method, TOPSIS method and PROMETHEE method. These algorithms vary in used normalization and weighting subroutines, which leads to the different complexities of these methods.

\section{MATERIAL AND METHODS}

\section{Problem formulation}

The market potential of the TCC systems is reflected in its application in construction of multi-storey residential and commercial buildings, which is presented in (Knauf 2017). The design guidelines of TCC structures are not explicitly given in any of the available structural design standards, except EN 1995-1-1 (2004). This standard does not consider design procedure in depth, but this should be changed with the development of new code generations. The future revision of Eurocode 5 should include a section dedicated to TCC systems (Dias et al. 2016). In design procedures for TCC systems, both serviceability and ultimate limit states under short-term and long-term loading should be considered. Although serviceability is generally considered less important than safety, the consequences of the serviceability failure may be significant in terms 
of costs (Honfi et al. 2012). In many design situations, particularly in residential and office buildings, acceptable performance of the structural system is seldom defined by ultimate limit state, but rather by serviceability requirements, especially by final deflection limit (Fragiacomo and Schänzlin 2013, Fragiacomo and Lukaszewska 2013).

The aim of the present study is to find the best solution for cross-sectional dimensions of the TCC beam by focusing on serviceability limit state (SLS) verification and cost of the TCC beam, simultaneously. The main goal of this process is to minimize the material being used in a structure and to reduce its overall weight without compromising its performances. Therefore, the size optimization study of TCC beams may present an opportunity to find material and cost savings within construction of the structures and it can be of practical value to structural designers.
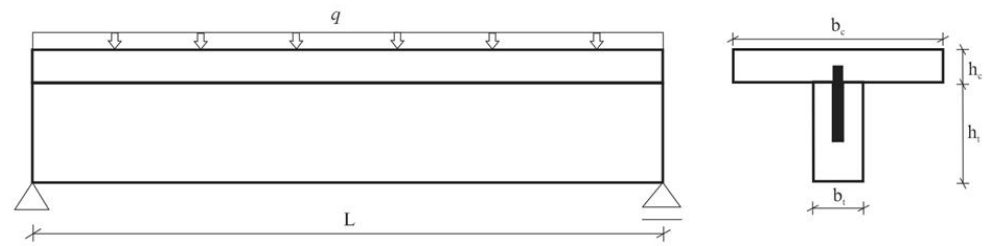

Fig. 1: Simply supported timber-concrete composite beam with mechanical fasteners.

In this study is considered simply supported TCC beam with mechanical fasteners as it is shown in Fig. 1. The input data of this optimization model shows geometrical characteristics of TCC cross section, observed connection system, mechanical characteristics of the componential materials and fasteners as well as loading and boundary conditions. Timber beam considered in this study has rectangular cross-section and it is performed of the spruce, sawn softwood timber structural strength class $\mathrm{C} 27$ with mechanical characteristics in accordance with the classification of structural timber with rectangular cross section (EN 338 2016). The concrete slab is made of concrete strength class C25/30 with characteristics according to EN 1992-1-1 (2004). Connection system, considered in this research, was achieved using glued-in steel rods made of the steel grade S235, which are often used to enhance old timber floors as well as for new construction works. In the pre-drilled holes, perpendicular to the grain and coated with epoxy resin, steel rods $\phi 20 / 150 \mathrm{~mm}$ are embedded at constant intervals of $s=240 \mathrm{~mm}$. We have considered TCC beams in indoor conditions, where temperature $(\mathrm{T})$ is $22 \pm 4^{\circ} \mathrm{C}$ and relative humidity $(\mathrm{RH})$ is $50 \pm 5 \%$. Based on Eurocode 5, these conditions correspond to the service class 1. According to the Eurocode recommendations (EN 1991-1-1 2002), for the areas for domestic and residential activities, the imposed load of $2 \mathrm{kN} \cdot \mathrm{m}^{-2}$ is suggested.

\section{Optimization variables}

In this study, geometrical characteristics of the cross-section of the TCC beam are observed as independent optimization variables: width of timber beam $(b t)$, height of the timber beam $(b t)$, height of the concrete slab $(b c)$ and width of the concrete slab $(b c)$. For the chosen optimization variables, it is necessary to define some constraints in terms of lower and upper bound that should define our research area. The appropriate range of optimization variables was defined based on EN 1995-1-1 (2004), recommendations of the EOTA (ETA-11/0270 2013) as well as based on the empirical recommendations. The other design parameters that are used for the calculation, such as material properties, characteristics of connection system, loading and boundary conditions are fixed during the optimization. 
Tab. 1: The constraints of optimization variables.

\begin{tabular}{|l|c|c|c|c|}
\hline \multicolumn{1}{|c|}{ Optimization variable } & Symbol & Dimension & Lower bound & Upper bound \\
\hline Width of timber beam & $b_{t}$ & $m m$ & 50 & 150 \\
\hline Height of timber beam & $h_{t}$ & $m m$ & 100 & 500 \\
\hline Height of concrete slab & $b_{c}$ & $m m$ & 50 & 100 \\
\hline Width of concrete slab & $b_{c}$ & $m m$ & 600 & 1000 \\
\hline
\end{tabular}

Typical spans for this type of constructions where the timber beam is made of sawn softwood are up to $8 \mathrm{~m}$ (ETA-11/0270 2013). According to that, we will conduct an optimization study on TCC beams with spans ranging between $4 \mathrm{~m}$ and $8 \mathrm{~m}$.

\section{Objective functions}

The most important SLS verification of the TCC beams is the control of the final deflection. The long-term behaviour of the TCC system is a very complex problem and it is not only affected by the long-term load but also by the long-term behaviour of the constituent materials. The variation of the environmental conditions such as temperature and relative humidity significantly affects the behavior of the materials employed in TCC system. The differential shrinkage/ swelling of the concrete flange and timber beam cannot freely occur due to the connection system that restrains the possibility of either part to move relative to the other. Consequently, additional deformations will be induced in the composite beam. Therefore, the design of such structures is usually conditioned by the maximum deflection in service. According to this fact, the first objective function is to minimize final mid-span deflection of the TCC beam.

The aim of the economical design is a cost-effective choice of shapes and sizes of structural elements. Therefore, the second objective function is to minimize the cost of the TCC beam. Considering that this composite system is still in the phase of development and introduction onto the market, cost estimation is a very difficult task. There are currently still learning effect costs, which make a calculation of the costs that exist on a long-term basis more difficult (Knauf 2017). Therefore, we defined cost of the TCC beam as follows:

$$
C(\boldsymbol{x})=c_{c} \cdot V_{c}+c_{t} \cdot V_{t}=\left(c_{c} \cdot b_{c} \cdot h_{c}+c_{t} \cdot b_{t} \cdot h_{t}\right) \cdot L
$$

where: $c_{c}$ and $c_{t}$ denote the relative costs of the manufacturing and embedding concrete and timber material per cubic meter, respectively.

Considering the current state of the market, we have assumed that relative cost of the timber is three times higher than relative cost of the concrete per cubic meter. The considered cost of the TCC beam does not contain cost of fasteners, since it is assumed that the number of fasteners for a particular beam length is constant for all optimization alternatives.

\section{Design constraints}

In order to avoid the deformations and other undesirable effects in service such as appearance/ comfort/functioning of the structure, the maximum deflection of the horizontal structural elements should be limited. According to the EN 1995-1-1 (2004), for the simply supported TCC beam, the limiting value of the final deflection is $\mathrm{L} / 200$, where $\mathrm{L}$ is the span of the TCC beam. In addition, based on the design recommendations presented in ETA-11/0270 (2013), we assumed that the ratio of the height of the concrete slab $\left(b_{c}\right)$ and the height of the timber beam $\left(h_{t}\right)$ is less than $70 \%$. 


\section{Multi-criteria decision-making background}

Weighting coefficients are often utilized for purpose of the criteria importance (Jahan et al. 2012, Zardari et al. 2015). Let us consider a multi-criteria model for ranking the alternatives $\left(A_{1}, \ldots, A_{m}\right)$ using $n$ criteria $\left(C_{1}, \ldots, C_{n}\right)$, where the value used to depict the alternative Ai satisfying the criterion $C_{j}$, is denoted by $a_{i j}$. The coefficients of alternatives with respect to criterion $C_{j}$ are given in the $j^{\text {th }}$ column of the decision matrix $D M=\left[a_{i j}\right]_{m \times n}$. Obviously, these standards may have dissimilar significance for the decision maker. For each criterion, the values of alternatives may be expressed using unequal units. Therefore, the decision matrix needs to be normalized in order to provide meaningful decisions. We have considered the vector normalization method, although there are many other normalization methods, and they can be found in (Jahan and Edwards 2015). Using this method, the normalized decision matrix $N D M=\left[q_{i j}\right]_{m \times n}$ is determined. Each element in this matrix belongs to the real unit interval $[0,1]$. However, all the criteria, which are of the minimization kind, are translated to the maximization kind by multiplying the values by -1 .

\section{The ranking of alternatives}

For $i=1,2, \ldots, \mathrm{m}, j=1,2, \ldots, \mathrm{n}$, elements qij determine the new normalized values of the alternative Ai using the criterion $\mathrm{C}_{j}$. Now, if $\mathrm{W}_{j}$ is the weight joined to the criterion $\mathrm{C}_{j}$, then we can consider the following equations to determine preference elements $e_{i j}$ associated with criteria $\mathrm{C}_{j}$.

$$
e_{i j}=W_{j} \cdot q_{i j}, \quad i=1, \ldots, m ; \quad j=1, \ldots, n .
$$

Next, the elements $e_{i j}(j=1,2, \ldots, n)$ should be summed to obtain the overall value of the alternative $A_{i}$ given by:

$$
V\left(A_{i}\right)=\sum_{j=1}^{n} e_{i j}
$$

Finally, ranking of the alternatives $A_{i}$ is constructed on the value of the aggregation (3) and the completion of criteria in the order of significance. For each two alternatives $A_{i}$ and $A j$ it is said that $\mathrm{Aj}$ is preferred over $\mathrm{A}_{i}$, notated as $\mathrm{A} j \rightarrow \mathrm{A}_{i}$, if and only if:

$$
\begin{aligned}
& V\left(A_{i}\right)<V\left(A_{j}\right) \\
& V\left(A_{i}\right)=V\left(A_{j}\right), \quad e_{i 1}<e_{j 1} \\
& \ldots \\
& V\left(A_{i}\right)=V\left(A_{j}\right), \quad e_{i 1}=e_{j 1}, \ldots, e_{i, n-1}=e_{j, n-1}, \quad e_{i n}<e_{j n}
\end{aligned}
$$

The best possible values for each criterion define ideal point in objective space:

$$
f^{*}=\left(f_{1}^{*}, f_{2}^{*}, \ldots, f_{n}^{*}\right)
$$

If there is solution ${ }_{\mathrm{x}}$ that minimizes all objective functions simultaneously:

$$
f_{j}\left(\boldsymbol{x}^{*}\right) \leq f_{j}(\boldsymbol{x}), \quad \forall \boldsymbol{x} \in X, j=1, \ldots, n
$$

where $f_{j}^{*}=f_{j}\left(x^{(j)^{*}}\right)$, then such a solution is called the ideal solution:

$$
\boldsymbol{x}^{*}=\left\{\boldsymbol{x} \mid f_{j}(\boldsymbol{x})=f_{j}^{*}, j=1, \ldots, n\right\}
$$


However, in real conditions there is no ideal solution, because in most of the cases multicriteria decision-making considers problem of conflicted objectives that cannot be satisfied simultaneously, therefore finding the optimal solution is very complicated. Pareto optimality has the main role in solving multi-criteria decision-making. Solution $x^{*} \in X$ is Pareto optimal of multicriteria decision making if there is no other feasible solution $\mathrm{x} \in \mathrm{X}$ that it is:

$$
f_{j}(\boldsymbol{x}) \leq f_{j}\left(\boldsymbol{x}^{*}\right), \quad \forall j=1, \ldots, n
$$

and that for at least one criterion there is no other feasible solution $\mathrm{x} \in \mathrm{X}$ that it is:

$$
f_{j}(\boldsymbol{x})<f_{j}\left(\boldsymbol{x}^{*}\right)
$$

However, Pareto optimality in most of the cases provides not just one solution, but a set of solutions where selecting any of them will sacrifice the quality of selection at least one of the criteria, while simultaneously improving at least one. This set of solutions is often called Pareto optimal set or Pareto front. The choice of the final solution of multi-criteria decision-making problem could be made either by decision maker or by corresponding to scalarization method.

\section{RESULTS AND DISCUSSION}

\section{Optimization alternatives}

The design procedure for TCC systems provided in EN 1995-1-1 (2004) is based on an approximate solution of the differential equation for beams with partial composite action. The proposed design method, $\gamma$-method, could be applied for the short-term verifications. For the long-term verifications, the Effective modulus method presented by Ceccotti (2002) is usually employed in order to account for the effect of creep of the constituent materials of the TCC. Based on the research carried out in recent years, it has been recognized that this approach has certain shortcomings and that is presented in the literature by different authors, Fragiacomo and Cecotti (2004), Fragiacomo (2006), Jorge et al. (2010), Kanócz et al. (2013), Kanócz and Bajzecerová (2014). The Effective Modulus method neglects phenomena such as the concrete shrinkage and inelastic strains of concrete and timber due to thermo-hygrometric environmental variations. Therefore, inclusion of all long-term effects related to constituent materials is highly recommended when accurate long-term analysis of TCC is required (Dias et al., 2018).

In order to generate relevant samples of optimization variables according to the predetermined ranges of optimization variables, Monte Carlo Sampling method (Kroese et al. 2014) was employed. Using this sampling method, we have generated the population of 10.000 samples of the observed optimisation variables. In order to investigate the effects of beam spans on the economical design of TCC beams, we have considered medium and long-span beams with spans ranging between $4 \mathrm{~m}$ and $8 \mathrm{~m}$. The optimization alternatives were formed on the basis of the observed criteria, the cost of the TCC beam and the final mid-span deflection. In order to analyze the influence of the phenomena, that are neglected in the Effective modulus method, on the economical design, we have formed two groups of alternatives. In the first group of alternatives (EC-SC1), the final deflection of the TCC beams was calculated according to the Effective modulus method, but in the second group of alternatives (INDOOR) using rigorous approach presented by Kanócz et al. (2013). Fig. 2 presents the trade-off charts of calculated optimization alternatives for the observed ranges of TCC beams. 

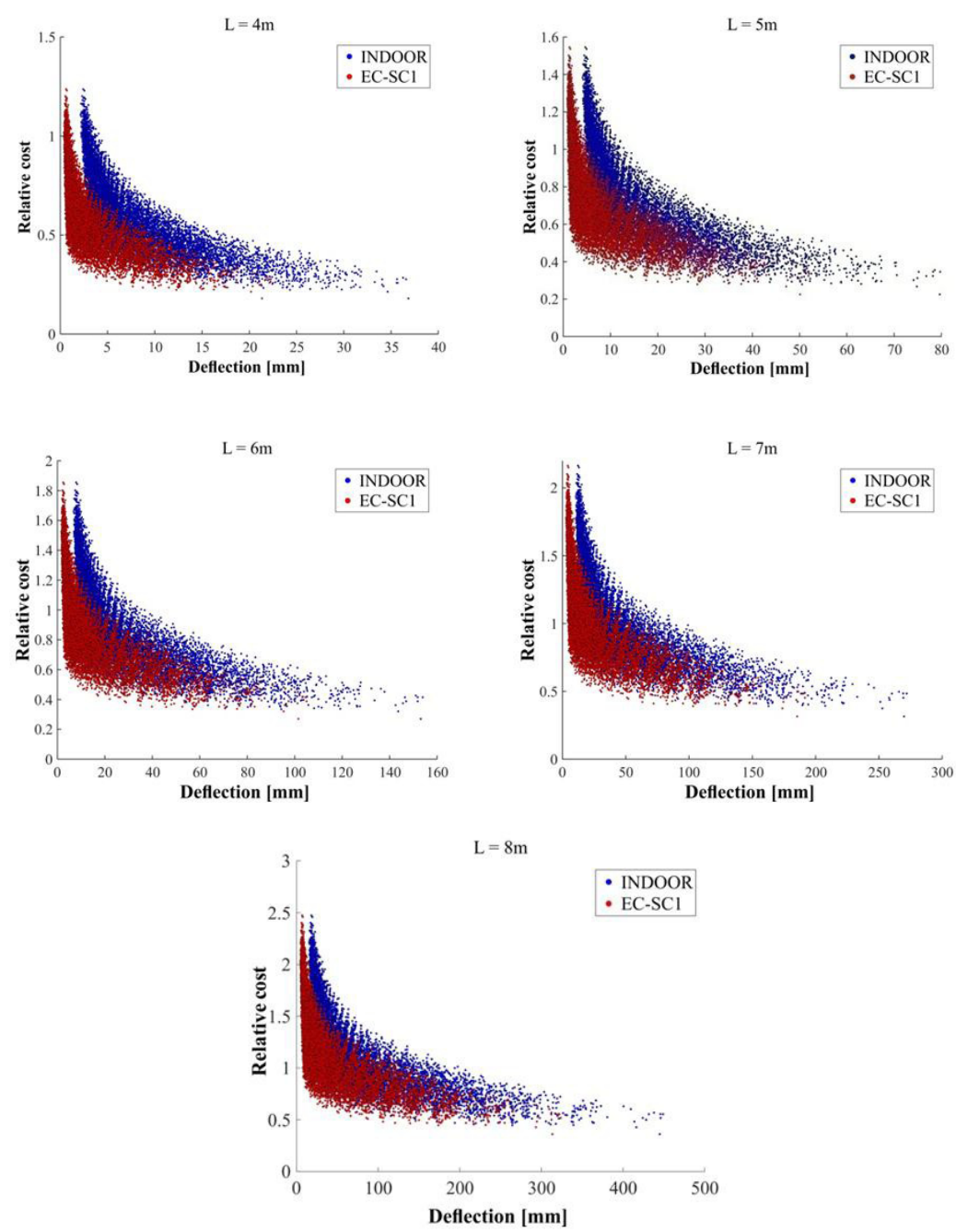

Fig. 2: Trade-off charts of alternatives for the considered spans of TCC beams.

Additionally, it provides us with a comparative analysis of the two observed approaches to calculate the final mid-span deflection of the TCC beams. In order to rank the alternatives, we have used a variation of the Weighted sum method as explained before. At the beginning, the decision matrix is given and weighting coefficients are specified for the cost and for deflection values. The implementation was performed based on generated algorithm: 
Algorithm: Calculation of the best alternatives

Input: Weights $w_{1}$ and $w_{2}$ for the cost and deflection, respectively; the number of alternatives $\boldsymbol{m}$

1: Perform the normalization of the decision matrix $\mathrm{C}$ :

$$
c_{i j}^{\prime}=\frac{c_{i j}}{\sum_{k=1}^{m} c_{k j}}, \quad 1 \leq i \leq m, \quad 1 \leq j \leq 2
$$

2: For each alternative $i, l \leq i \leq m$ calculate the weighted sum of the cost and deflection as:

$$
d_{i}=w_{l} \cdot c_{i l}+w_{2} \cdot c_{i 2}
$$

3: Sort the alternatives (rows in matrix $\mathrm{C}$ ) by the value of $\mathrm{di}$, from largest to smallest values, and denote the new matric by $\mathrm{D}$.

4: Return the first $\mathrm{n}$ rows of the matrix $\mathrm{D}$ as the result.

\section{Minimum relative cost of the TCC beam}

Firstly, we have conducted optimization analysis using generated algorithm, where the weighting coefficient for the beam cost was adopted equal to 1 . The result of this analysis is the minimum relative cost of the TCC beam so that the serviceability requirements are satisfied. This analysis has also considered the two different approaches for the calculation of the final midspan deflection, which were previously exposed. In the Tab. 2 are summarized the second-order polynomial fits between the minimum relative costs and the spans of the TCC beams. These results can be used to get an initial estimation of the costs under a given span length.

Tab. 2: Polynomial best-fit equations for minimum relative cost of the TCC beams.

\begin{tabular}{|c|c|c|}
\hline Model & Polynomial best-fit equation & Coefficient of determination $\mathbf{( R}^{\mathbf{2}} \mathbf{~}$ \\
\hline EC-SC1 & $0.008853 \cdot \mathrm{L}^{2}-0.07567 \cdot \mathrm{L}+0.1131$ & 0.9994 \\
\hline INDOOR & $0.005708 \cdot \mathrm{L}^{2}+0.06426 \cdot \mathrm{L}-0.1195$ & 0.9966 \\
\hline
\end{tabular}

Fig. 3 shows the results of the conducted optimization analysis and the polynomial best fits of those results.

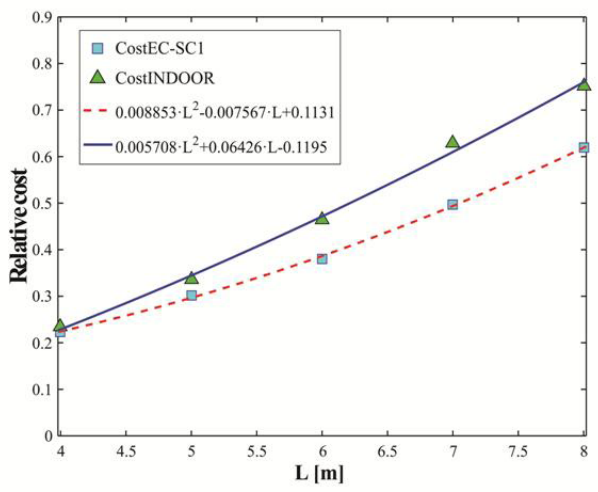

Fig. 3: Minimum relative cost of the TCC beam. 
The first curve gives an overview of the obtained results based on the Effective modulus method (CostEC-SC1), while the other curve is formed using results gained by the advanced rigorous approach (CostINDOOR). It is noticeable that both curves have the same non-linear trend that increases with the beam span. Based on the presented analysis results, we can conclude that the minimum relative cost of the TCC beam can be increased even by $26.6 \%$ if the rheological effects that are neglected by the Effective modulus method are counted in the calculation of the final deflection. The benefit of the conducted optimization analysis could be the required TCC beam depth. Polynomial best-fits of these results are tabled in Tab. 3 .

Tab. 3: Polynomial best-fit equations for required TCC beam depth.

\begin{tabular}{|l|c|c|}
\hline \multicolumn{1}{|c|}{ Model } & Polynomial best-fit equation & Coefficient of determination $\left(\mathbf{R}^{2}\right)$ \\
\hline EC-SC1 & $2.417 \cdot \mathrm{L}^{2}+5.53 \cdot \mathrm{L}+129.1$ & 0.9829 \\
\hline INDOOR & $-1.042 \cdot \mathrm{L}^{2}+70.84 \cdot \mathrm{L}-63.45$ & 0.9991 \\
\hline
\end{tabular}

Based on the Fig. 4, we can see that the required depth of the TCC cross section should be increased even by $36.7 \%$ compared to the case where the differential shrinkage is neglected. Therefore, the usual practice of neglecting differential shrinkage leads to a significant underestimation of the final deflection. This analysis gives us the opportunity to offer the recommended span/depth ratio for the TCC beams.

Based on the results obtained using the Effective modulus method, this ratio is approximately 23.4. However, if we include all the long-term effects related to constituent materials that are ignored by this method, the average value of the span/depth ratio is 18.7. These results should prove useful to structural designers and is expected to advance existing design practices of TCC beams.

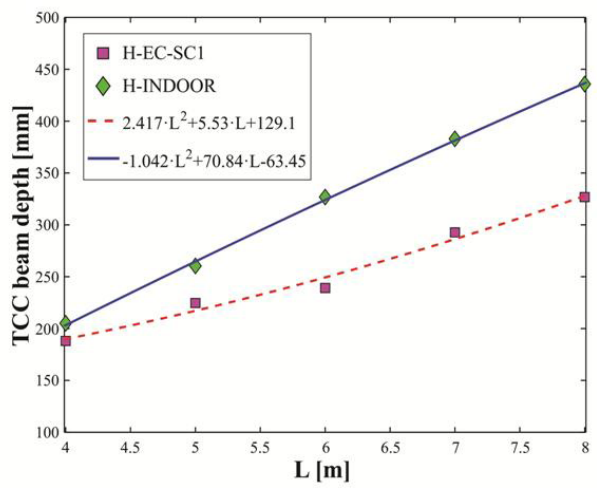

Fig. 4: Required TCC beam depth.

\section{Trade-off strategy in design of the TCC beams}

When the large number of design options need to be evaluated according to the considered criteria, it is very helpful to present them in the objective space, as it is shown in Fig. 2. The outer boundary of this set of optimization alternatives would define the borderline limit beyond which design cannot be further improved. In the multi-objective decision-making, this borderline presents the Pareto front that separates the feasible and infeasible regions. The feasible region is defined as the set of feasible solutions, for which all constraints are satisfied. When the value of one objective function of the Pareto-optimal solution is decreasing, while keeping the value of the 
other objective function constant, this would move that design option into the infeasible region. Increasing the value of one objective function, while keeping the value of the other objective function constant, would no longer make the design optimal. In order to find a number of Paretooptimal solutions on the Pareto front, the weighting coefficients for both objectives have been varied using previously presented algorithm.

In this study, we have carried out the multi-criteria decision making process using alternatives where final deflection of the TCC beam is obtained by advanced approach that include all the long-term effects related to constituent materials.
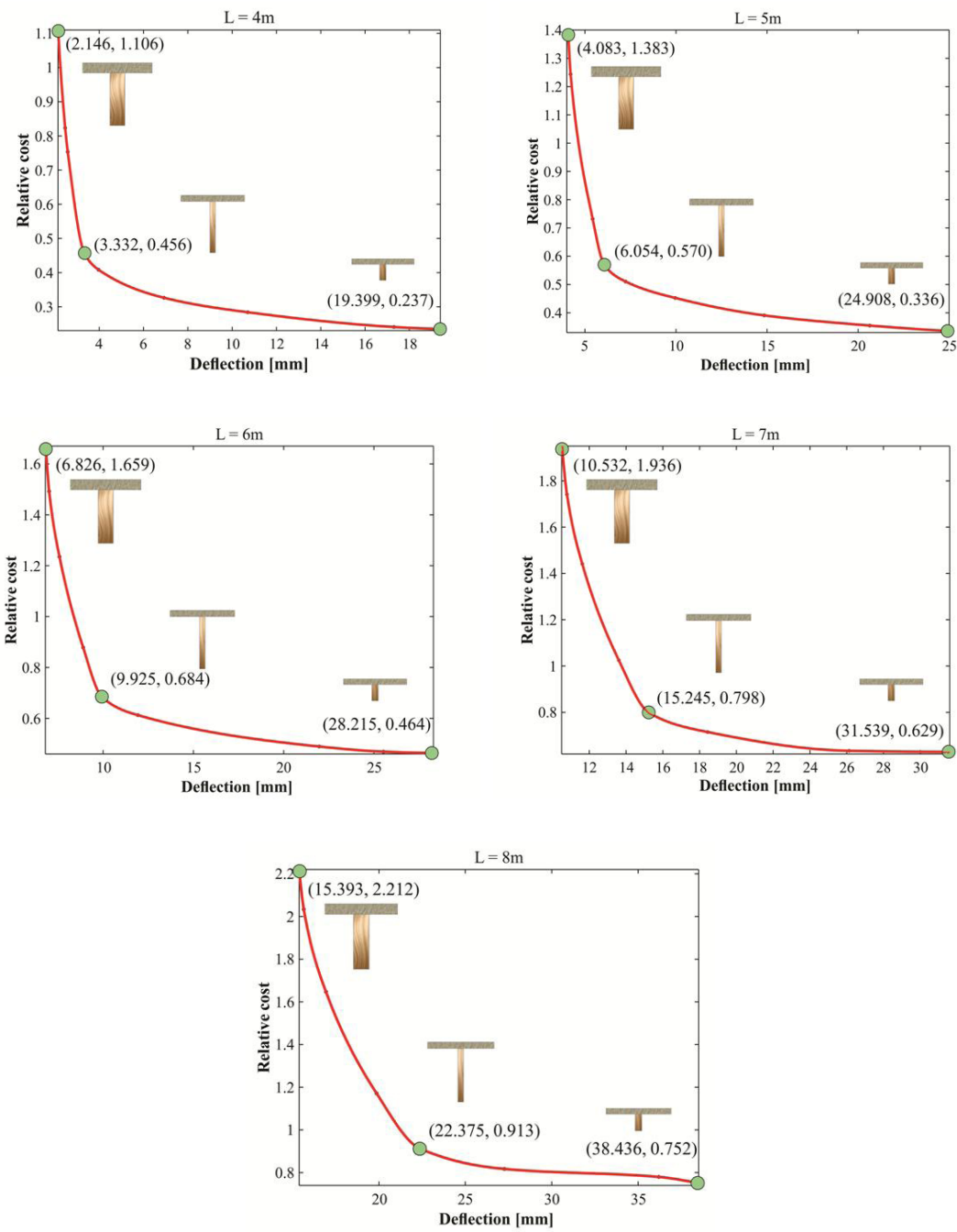

Fig. 5: Design proposals of TCC beams obtained by selecting different solutions of the Pareto front. 
Fig. 5 shows Pareto fronts for different beam spans and some possible designs of TCC cross section obtained by selecting different Pareto-optimal solutions of the Pareto front. We can see that the first objective function, deflection, dominates the design process compared to the relative cost function. Fig. 5 provides some samples of changing geometry of the TCC cross section along the Pareto front and allows us to see how becomes robust when taking Pareto-optimal solutions from the right to the left part of the Pareto front.

Analyzing the results of the performed size optimization, we can see that with an increase in the relative price of the TCC beam with span $4 \mathrm{~m}$ for only $2.62 \%$ compared to the minimum relative cost of the beam, we could obtain the Pareto optimal solution for which the mid-span deflection of the beam is reduced by $10.81 \%$. A similar situation is with the 5-meter long beam. When the relative cost of the beam is increased by $5.77 \%$ compared to its minimum value, we can have composite beam which maximum deflection in the end of the service life is reduced by 17.14\%. Using trade-off strategy in the design of the TCC beam with span of $6 \mathrm{~m}$, we could get even better improvements in design process. Increasing the relative cost for only $1.09 \%$ related to its minimum value, we will get TCC beam which final deflection is reduced by $9.52 \%$, or with an increase of $5.48 \%$ of the relative cost, the final deflection is reduced by $22.14 \%$. In the case of the TCC beam of $7 \mathrm{~m}$, we have the possibility to get the design option of the cross-section whereby the final deflection could be decreased by $17.15 \%$ with an increase of the minimum relative cost for only $0.73 \%$, or even better design option with cost increase of $13.63 \%$ to get TCC beam with decreased final deflection for even $41.54 \%$. Finally, in the case of the longest observed TCC beam with the span of $8 \mathrm{~m}$, we could improve design of the beam with an increase of the relative cost for $8.69 \%$, but we could get the composite beam which final deflection is decreased by $29.08 \%$.

Financial savings are an obvious potential driver for use of the structural optimization. However, based on the presented trade-off strategy in design of the TCC beams, we can see that with the slight increase of relative cost it is possible to get Pareto optimal design solution of the TCC beam that has drastically decreased final deflection and therefore is a more reliable design solution.

\section{CONCLUSIONS}

In order to find economical solution for cross-sectional dimensions of the timber-concrete composite (TCC) beam, size optimization has been conducted by focusing on final mid-span deflection and cost of the TCC beam, simultaneously.

Based on the presented analysis results, it was concluded that the minimum relative cost of the TCC beam can be increased even by $26.6 \%$ if the rheological effects that are neglected by the Effective modulus method are counted in the calculation of the final deflection. In addition, it can be seen that the required depth of the TCC cross section should be increased even by $36.7 \%$ compared to the case where the differential shrinkage is neglected. This analysis gives the opportunity to offer the recommended span/depth ratio for the TCC beams. Based on the results obtained using the effective modulus method, this ratio is approximately 23.4. However, if we include all the long-term effects related to constituent materials that are ignored by this method, the average value of the span/depth ratio is 18.7. Therefore, we can conclude that the usual practice of neglecting differential shrinkage leads to a significant underestimation of the final deflection. Therefore, inclusion of all long-term effects related to constituent materials is highly recommended when accurate long-term analysis of TCC is required. The weighted sum method was applied in order to find a number of Pareto-optimal solutions on the Pareto front using presented original algorithm. Financial savings are an obvious potential driver for use of 
the structural optimization. However, based on the presented trade-off strategy in design of the TCC beams, we can see that with the slight increase of relative cost compared to the minimum, it is possible to get Pareto optimal design solution of the TCC beam that has drastically decreased final deflection and therefore more reliable design solution. The Pareto fronts for different considered beam spans were presented as well as some representative samples of TCC cross section obtained by selecting different Pareto-optimal solutions.

\section{REFERENCES}

1. Ceccotti, A., 2002: Composite concrete-timber structures. Progress in Structural Engineering and Materials 4(3): 264-275.

2. Christensen, P.W., Klarbring, A., 2009: An introduction to structural optimisation. Springer Science \& Business Media. Netherlands, 214 pp.

3. Dias, A.M.P.G., Martins, A.R.D., Simões, L.M.C., Providência, P.M., Andrade, A.A.M., 2015: Statistical analysis of timber-concrete connections-Mechanical properties. Computers \& Structures 155: 67-84.

4. Dias, A., Skinner, J., Crews, K., Tannert, T., 2016: Timber-concrete-composites increasing the use of timber in construction. European Journal of Wood and Wood Products 74(3): 443-451.

5. Dias, A., Schänzlin, J., Dietsch, P. (eds.), 2018: Design of timber-concrete composite structures: A state-of-the-art report by COST Action FP1402 / WG 4, Shaker Verlag Aachen, 228 pp.

6. EN 1991-1-1, 2002: Eurocode 1: Actions on structures. Part 1-1: General actions Densities, self-weight, imposed loads for buildings.

7. EN 1992-1-1, 2004: Eurocode 2: Design of Concrete Structures. Part 1-1: General Rules and Rules for Buildings.

8. EN 1995-1-1, 2004: Eurocode 5: Design of timber structures. Part 1-1: General - Common rules and rules for buildings.

9. EN 338, 2016: Structural timber. Strength classes.

10. ETA-11/0270, 2013: Self-tapping screws for use in wood-concrete slab kits.

11. Fragiacomo, M., 2006: Long-term behavior of timber-concrete composite beams. II: Numerical analysis and simplified evaluation. Journal of Structural Engineering 132(1): 23-33.

12. Fragiacomo, M., Ceccotti, A., 2004: A simplified approach for long-term evaluation of timber-concrete composite beams. In: Proceedings of the 8th World Conference on Timber engineering. Finnish Association of Civil Engineers RIL. Lahti, Finland. Pp. 537-542.

13. Fragiacomo, M., Lukaszewska, E., 2013: Time-dependent behaviour of timber-concrete composite floors with prefabricated concrete slabs. Engineering Structures 52: 687-696.

14. Fragiacomo, M., Schänzlin, J., 2013: Proposal to account for concrete shrinkage and environmental strains in design of timber-concrete composite beams. Journal of Structural Engineering 139(1): 162-167.

15. Honfi, D., Martensson, A., Thelandersson, S., 2012: Reliability of beams according to Eurocodes in serviceability limit state. Engineering Structures 35: 48-54.

16. Jahan, A., Edwards, K.L., 2015: A state-of-the-art survey on the influence of normalization techniques in ranking: Improving the materials selection process in engineering design. Materials and Design 65: 335-342. 
17. Jahan, A., Mustapha, F., Sapuan, S.M., Ismail, M.J., Bahraminasab, M., 2012: A framework for weighting of criteria in ranking stage of material selection process. The International Journal of Advanced Manufacturing Technology 58(14): 411-420.

18. Jorge, L.F., Schänzlin, J., Lopes, S.M.R., Cruz, H., Kuhlmann, U., 2010: Time-dependent behaviour of timber lightweight concrete composite floors. Engineering Structures 32(12): 3966-3973.

19. Kanócz, J., Bajzecerová, V., Šteller, Š., 2013: Timber - concrete composite elements with various composite connections part 1: screwed connection. Wood Research 58(4): 555-570.

20. Kanócz, J., Bajzecerová, V., 2014: Parametric analysis of long-term behaviour of timberconcrete composite bended elements. Wood Research 59(3): 379-388.

21. Knauf, M., 2017: Market potentials for timber-concrete composites in Germany's building construction sector. European Journal of Wood and Wood Products 75(4): 639-649.

22. Kroese, D.P., Brereton, T., Taimre, T., Botev, Z.I., 2014: Why the Monte Carlo method is so important today. WIREs Computational Statistics 6(6): 386-392.

23. Lukaszewska, E., Johnsson, H., Fragiacomo, M., 2008: Performance of connections for prefabricated timber-concrete composite floors. Materials and Structures 41(9): 1533-1550.

24. Yeoh, D., Fragiacomo, M., De Franceschi, M., Boon, K.H., 2011: State of the art on timber-concrete composite structures: literature review. Journal of Structural Engineering 137(10): 1085-1095.

25. Zardari, N.H., Ahmed, K., Shirazi, S.M., Yusop, Z.B., 2015: Weighting methods and their effects on multi-criteria decision making model outcomes in water resources management. Springer. Cham, 166 pp.

\author{
Nikola Velimirović* \\ State University of Novi Pazar \\ Department of Technical Sciences \\ 36300 Novi Pazar \\ Serbia
}

*Corresponding author: velimirovic.nikola@gmail.com

IVAN Stanimirović

UNIVERSITY OF Niš

Faculty of Science and Mathematics

I 8000 Niš

Serbia

Dragoslav Stojić, Nemanja Marković

UNiversity OF Niš

Faculty of Civil Engineering and Architecture

I 8000 Niš

Serbia 
Ruhr-University Bochum

Faculty of Civil and Environmental Engineering

448or Bochum

Germany

Milivoje Milanović

State University of Novi Pazar

Department of Technical Sciences

36300 Novi Pazar

Serbia 